\title{
Smartphone Application Technology In Control Robot In Search Focal Point (Pengaplikasian Teknologi Smartphone Dalam Pengontrolan Robot Dalam Pencarian Titik Api)
}

\author{
Nanda Tommy Wirawan \\ Universitas Putra Indonesia YPTK Padang \\ e-mail : nandatommyw@upiyptk.ac.id
}

\begin{abstract}
Abstrak
Pemanfaatan Teknologi Smartphone dalam penelitian ini bertujuan untuk mengontrol Robot dalam mencari titik api sehingga kita bisa mengetahui titik api dari sudut mana pun. Dan Robot bisa di atur secara otomatis dalam pencarian titik api tanpa harus dikendalikan. Apabila robot menemukan titik api maka robot akan memberitahukan ke Smartphone bahwa api ditemukan. Untuk jalur komunikasi Robot dan Smartphone menggunakan Bluetooth HC-05. Penelitian ini bertujuan untuk mempermudah manusia menemukan titik api didalam ruangan yang sempit dan yang susah untuk dilewati. Sehingga pencegahan pun cepat dilakukan agar tidak merambat ke yang lebih besar. Dalam hasil penelitian ini menunjukkan bahwa Robot yang dibuat berfungsi dengan baik dan dapat dikembangkan untuk skala yang lebih besar.
\end{abstract}

Kata kunci: Robot, Smartphone, Flame Sensor, Bluetooth.

\begin{abstract}
Smartphone Technology Utilization in this research aims to control the robot in finding hotspots so that we can know the point of fire from any angle. And the robot can be set automatically in the search for hotspots without having to be controlled. When the robots find fire robot will notify to the Smartphone that fire was found. For communication lines and Smartphone Robot uses HC-05 Bluetooth.This study aims to facilitate human find fire in the room is cramped and difficult to pass. So prevention was quickly taken not to spread to a larger one. In the results of this study indicate that the robot is made to function properly and can be expanded to a larger scale,
\end{abstract}

Keywords: Robot, Smartphone, Flame Sensor, Bluetooth.

\section{PENDAHULUAN}

Robot adalah seperangkat alat mekanik yang bisa melakukan tugas fisik, baik dengan pengawasan dan kontrol manusia, ataupun menggunakan program yang telah didefinisikan terlebih dulu (kecerdasan buatan). Robot biasanya digunakan untuk tugas yang berat, berbahaya, pekerjaan yang berulang dan kotor. Biasanya kebanyakan robot industri digunakan dalam bidang produksi. Penggunaan robot lainnya termasuk untuk pembersihan limbah beracun, penjelajahan bawah air dan luar angkasa, pertambangan, pekerjaan "cari dan tolong" (search and rescue), dan untuk pencarian tambang. Dan pada saat ini sudah banyak kasus kebakaran yang terjadi di Indonesia terutama pada perusahaan perusahaan industri atau pun rumah. Walaupun diperusahaan sudah menyiapkan pendeteksi kebakaran. Tetapi tanpa pengawasan api yang sekecil apapun akan susah terdeteksi oleh pendeteksi kebakaran. Karena pendeteksi kebakaran hanya mendeteksi api ketika sudah mulai besar. Dan itu sangat susah dicegah karena api akan cepat merambat ke daerah yang lain. Sistem kontrol telah terbukti menjadi alat yang sangat berguna dalam bidang robotika otomatis, ditandai dengan ketidakpastian yang tinggi dalam pengetahuan tentang lingkungan di mana robot berkembang untuk mengembangkan strategi kontrol untuk mobile robot menggunakan logika Fuzzy. Kami mengusulkan strategi kontrol gerak berdasarkan kontrol Fuzzy logic sehingga mencapai posisi / lokasi yang diinginkan [8]. Perkembangan kontrol sepenuhnya otomatis, sistem untuk mobile robot dimungkinkan karena kekuatan peningkatan sumber daya komputasi. Dengan perkembangan tersebut, banyak skema 
kontrol telah diusulkan untuk menangani masalah kontrol seperti jaringan saraf dan kontrol Fuzzy. Teknik berdasarkan Fuzzy Logic telah berhasil diterapkan untuk membangun sistem kontrol mobile cerdas [9].

Sehingga Peneliti membuat sebuah ide dalam penanganan kasus kebakaran yang banyak terjadi bada perusahaan ataupun dirumah. Dengan adanya robot pemantau api kita bisa mendeteksi kebakaran api yang masih kecil ataupun percikan-percikan yang akan memicu kebakaran akan terdeteksi oleh robot dan akan diberitahukan kepada pengawas melalui aplikasi Smartphone bahwa ada api ataupun percikan. Sehingga kita bisa mengantisipasi dampak yang lebih besar yang akan terjadi nanti. Dan robot akan selalu mengawasi daerah yang telah kita set terlebih dahulu.

\section{LANDASAN TEORI}

\subsection{Robot}

Istilah robot pertama kali diperkenalkan dalam bahasa Inggris pada tahun 1921 oleh seorang dramawan Cekoslowakia yang bernama Karel Capek dalam dramanya yang berjudul R.U.R (Rossum's Universal Robots). Robot dalam arti mula-mula adalah “forced labour" yang berarti pekerja paksa, namun dalam pengertian modern kata robot sudah mengalami perluasan makna. Menurut The Robotics International Division of The Society of Manufacturing Engineers (RI/SME), robot dapat didefinisikan sebagai manipulator reprogrammable dan multifungsi yang dirancang untuk memindahkan material , bagian, peralatan, dan perangkat khusus melalui variabel gerakan yang diprogram untuk kinerja berbagai tugas [10].

\subsection{Arduino UNO}

Arduino Uno adalah board mikrokontroler berbasis ATmega328. Uno memiliki 14 pin digital input / output (dimana 6 dapat digunakan sebagai output PWM), 6 input analog, resonator keramik $16 \mathrm{MHz}$, koneksi USB, jack listrik, header ICSP, dan tombol reset. Uno dibangun berdasarkan apa yang diperlukan untuk mendukung mikrokontroler, sumber daya bisa menggunakan power USB (jika terhubung ke komputer dengan kabel USB) dan juga dengan adaptor atau baterai.

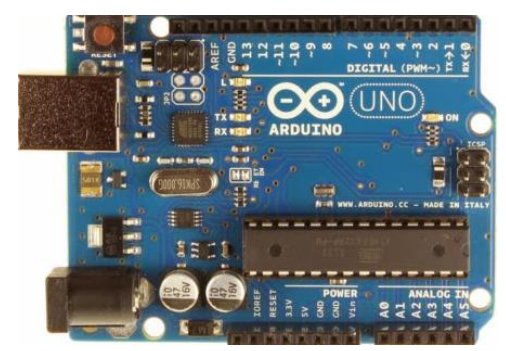

Gambar 2.1 Arduino Uno

\subsection{Driver Motor L298N}

L298 aadalah driver motor berbasis H-Bridge, mampu menangani beban hingga 4A pada tegangan $6 \mathrm{~V}-46 \mathrm{~V}$. Dalam chip terdapat dua rangkaian H-Bridge. Selain itu driver ini mampu mengendalikan 2 motor sekaligus dengan arus beban 2 A. berikut gambar rangkaian driver motor L298. 


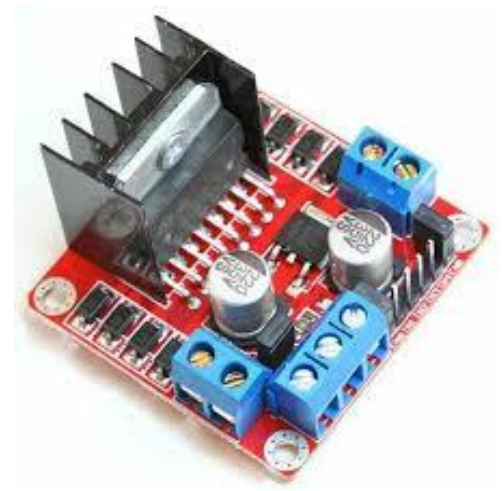

Gambar 2.2 Arduino Uno

Rangkaian driver motor yang terlihat pada gambar 2.2, untuk outputmotor DC digunakan dioda, hal ini ditujukan agar driver motor dapat menahan arus balik yang datang dari motor DC. Input driver motor berasal dari mikrokontroler utama, untuk MOT 1A dan MOT 1B untuk menggerakan motor 1, ENABLE 1 untuk mengatur kecepatan motor 1 menggunakan PWM, selanjutnya untuk MOT 2A dan MOT 2B untuk menggerakan motor 2, ENABLE 2 untuk mengatur kecepatan motor 2 menggunakan PWM.

Tabel 2.1 Kebenaran Untuk 2 Motor

\begin{tabular}{|l|l|l|l|l|l|l|}
\hline $\begin{array}{l}\text { MOT } \\
\text { A }\end{array}$ & $\begin{array}{l}\text { MOT } \\
\text { 1B }\end{array}$ & ENB 1 & $\begin{array}{l}\text { MOT } \\
\text { 2A }\end{array}$ & $\begin{array}{l}\text { MOT } \\
\text { 2B }\end{array}$ & $\begin{array}{l}\text { ENB } \\
2\end{array}$ & GERAK \\
\hline H & L & H & H & L & H & Maju \\
\hline L & H & H & L & H & H & Mundur \\
\hline H & L & H & L & L & H & Belok kanan \\
\hline L & L & H & H & L & H & Belok kiri \\
\hline
\end{tabular}

Secara konsep rangkaian ini terdiri dari 4 saklar yang tersusun sedemikian rupa sehingga memungkinkan motor dapat teraliri arus dengan arah yang berkebalikan. Yaitu searah jarum jam dan berlawanan arah jarum jam. Pada rangkaian driver motor ini, saklar-saklar tersebut digantikan oleh transistor atau MOSFET yang dikerjakan pada daerah saturasi dan cut-off (Switch). Berikut cara kerja dari H-Bridge motor.

\subsection{Sensor Ultrasonic SRF04}

Gelombang ultrasonik merupakan gelombang mekanik longitudinal (gelombang yang amplitudonya berubah-ubah) dengan frekuensi di atas $20 \mathrm{kHz}$. Gelombang ini dapat merambat dalam medium padat, cair dan gas, hal ini disebabkan karena gelombang ultrasonik merupakan rambatan energi dan momentum mekanik sehingga merambat sebagai interaksi dengan molekul dan sifat enersia medium yang dilaluinya

Ultrasonic SRF04 mempunyai 2 buah pin kontrol, antara lain sebuah pin input triger dan sebuah pin output data. Untuk mengaktifkan sensor maka modul diberi triger pulsa maka sensor akan mengeluarkan sinyal pwm dan duty cycle tersebut sebagai jarak objek dengan sensor. Mikrokontroller memberikan sinyal pulsa high pada pin triger pulse input dari sensor untuk mengaktifkan sensor ultrasonik. Untuk menghitung lebar PWM mengunakan timer0. Pin echo pulse output terhubung dengan pin-pin pada mikrokontroler. Ketika pin echo pulse output high maka timer0 aktif dan ketika pin echo kembali bernilai low maka timer0 dimatikan dan data TCNT0 diambil sebagai data jarak. Berikut pada gambar 2.3 adalah cara kerja sensor ultrasonik.

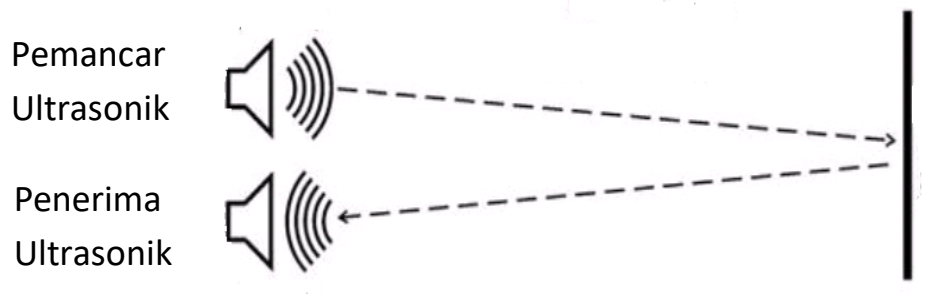

Gambar 2.3 Prinsip Kerja Sensor Ultrasonik 


\subsection{Bluetooth $\mathrm{HC}-05$}

HC-05 Adalah sebuah modul Bluetooth SPP (Serial Port Protocol) yang mudah digunakan untuk komunikasi serial wireless (nirkabel) yang mengkonversi port serial ke Bluetooth. HC-05 menggunakan modulasi bluetooth V2.0 + EDR (Enchanced Data Rate) 3 Mbps dengan memanfaatkan gelombang radio berfrekuensi 2,4 GHz. Modul ini dapat digunakan sebagai slave maupun master. HC-05 memiliki 2 mode konfigurasi, yaitu AT mode dan Communication mode. AT mode berfungsi untuk melakukan pengaturan konfigurasi dari HC-05. Sedangkan Communication mode berfungsi untuk melakukan komunikasi bluetooth dengan piranti lain.

Dalam penggunaannya, HC-05 dapat beroperasi tanpa menggunakan driver khusus. Untuk berkomunikasi antar Bluetooth, minimal harus memenuhi dua kondisi berikut :

1. Komunikasi harus antara master dan slave.

2. Password harus benar (saat melakukan pairing).

Jarak sinyal dari HC-05 adalah 30 meter, dengan kondisi tanpa halangan. Untuk gambar module bluetooth dapat dilihat pada gambar 2.4 .

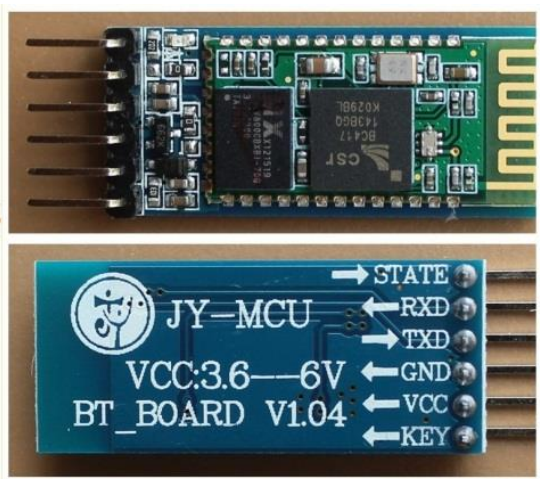

\section{Gambar 2.4 Module Bluetooth HC-05}

Berikut merupakan konfigurasi pin bluetoooth HC-05 ditunjukkan pada tabel 2.1 dibawah ini:

Tabel 2.2 Konfigurasi Pin Module Bluetooth HC-05

\begin{tabular}{|l|l|l|}
\hline \multicolumn{1}{|c|}{ Nomor Pin } & \multicolumn{1}{|c|}{ Nama } & \multicolumn{1}{c|}{ Fungsi } \\
\hline Pin 1 & Key & - \\
\hline Pin 2 & VCC & Sumber Tegangan 5V \\
\hline Pin 3 & GND & Ground Tegangan \\
\hline Pin 4 & TXD & Mengirim Data \\
\hline Pin 5 & RXD & Menerima Data \\
\hline Pin 6 & STATE & - \\
\hline
\end{tabular}

\subsection{Motor DC}

Motor Listrik DC atau DC Motor adalah suatu perangkat yang mengubah energi listrik menjadi energi kinetik atau gerakan (motion). Motor DC ini juga dapat disebut sebagai Motor Arus Searah. Seperti namanya, DC Motor memiliki dua terminal dan memerlukan tegangan arus searah atau DC (Direct Current) untuk dapat menggerakannya. Motor Listrik DC ini biasanya digunakan pada perangkat-perangkat Elektronik dan listrik yang menggunakan sumber listrik DC seperti Vibrator Ponsel, Kipas DC dan Bor Listrik DC.

Motor Listrik DC atau DC Motor ini menghasilkan sejumlah putaran per menit atau biasanya dikenal dengan istilah RPM (Revolutions per minute) dan dapat dibuat berputar searah jarum jam maupun berlawanan arah jarum jam apabila polaritas listrik yang diberikan pada Motor DC tersebut dibalikan. 
Motor Listrik DC tersedia dalam berbagai ukuran rpm dan bentuk. Kebanyakan Motor Listrik DC memberikan kecepatan rotasi sekitar $3000 \mathrm{rpm}$ hingga $8000 \mathrm{rpm}$ dengan tegangan operasional dari 1,5V hingga $24 \mathrm{~V}$. Apabile tegangan yang diberikan ke Motor Listrik DC lebih rendah dari tegangan operasionalnya maka akan dapat memperlambat rotasi motor DC tersebut sedangkan tegangan yang lebih tinggi dari tegangan operasional akan membuat rotasi motor DC menjadi lebih cepat.

Namun ketika tegangan yang diberikan ke Motor DC tersebut turun menjadi dibawah $50 \%$ dari tegangan operasional yang ditentukan maka Motor DC tersebut tidak dapat berputar atau terhenti. Sebaliknya, jika tegangan yang diberikan ke Motor DC tersebut lebih tinggi sekitar 30\% dari tegangan operasional yang ditentukan, maka motor DC tersebut akan menjadi sangat panas dan akhirnya akan menjadi rusak. Bentuk dan Simbol Motor DC dapat dilihat pada gambar 2.5.
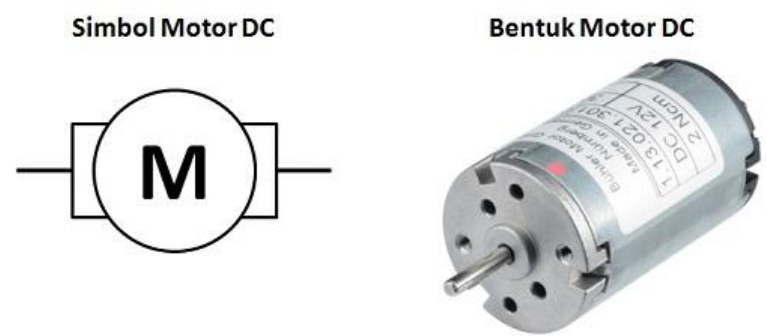

Gambar 2.4 Bentuk dan Simbol Motor DC

\subsection{Sensor Flame}

Flame sensor merupakan sensor yang mempunyai fungsi sebagai pendeteksi nyala api yang dimana api tersebut memiliki panjang gelombang antara 760nm - 1100nm. Sensor ini menggunakan infrared sebagai tranduser dalam mensensing kondisi nyala api. Dalam kebanyakan pertandingan kompetisi robot, pendeteksian akan nyala api misalnya lilin masih tetap jadi salah satu aturan yang umum dalam kompetensi lomba yang tidak akan pernah ditinggalkan. Dikarena itulah sensor ini mempunyai peran yang vital yang berfungsi sebagai "mata" bagi robot dalam menyelesaikan tugasnya menemukan posisi nyala api.

Sensor ini sering juga digunakan untuk mendeteksi api pada ruangan di perkantoran, apartemen, maupun di perhotelan. Suhu normal pembacaan normal sensor ini yaitu pada $25-85^{\circ} \mathrm{C}$ dengan besar sudut pembacaan pada $60^{\circ}$. Dengan memperhatikan jarak sensing antara objek yang akan disensing dengan sensor tidak boleh terlalu dekat, yang berakibat lifetime sensor yang cepat rusak.

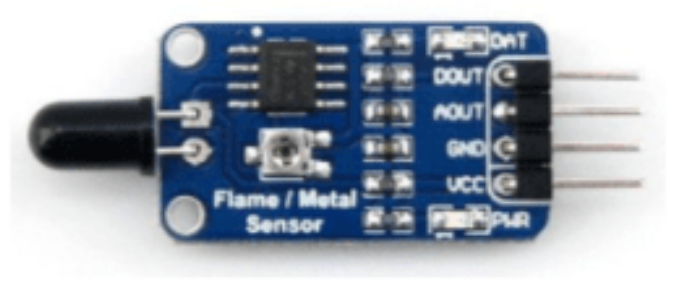

\section{Gambar 2.4 Bentuk Sensor Flame}

\subsubsection{Cara Kerja Sensor Flame}

Cara kerja sensor ini yaitu dengan mengidentifikasi atau mendeteksi nyala api dengan menggunakan metode optik. Pada sensor ini menggunakan tranduser yang berupa infrared (IR) sebagai sensing sensor. Tranduser ini digunakan untuk mendeteksi akan penyerapan cahaya pada panjang gelombang tertentu. Yang dimana memungkinkan alat ini untuk membedakan antara spectrum cahaya pada api dengan spectrum cahaya lainnya seperti spectrum cahaya lampu. Berikut adalah contoh simulasi sensor flame menggunakan software "Proteus". 


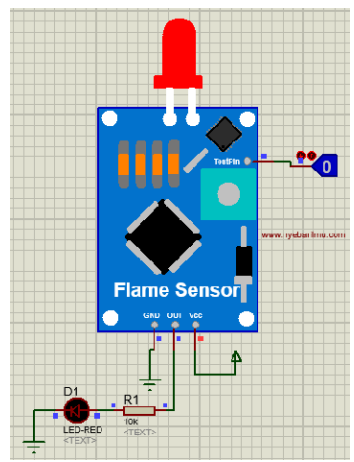

Gambar 2.4 Simulasi Proteus dengan Sensor Flame

Fitur dari flame sensor :

- $\quad$ Tegangan operasi antara 3,3-5 Vdc

- Terdapat 2 output yaitu digital output dan analog output yang berupa tegangan

- Sudah terpackage dalam bentuk modul

- Terdapat potensiometer sebagai pengaturan sensitivitas sensor dalam mensensing

\section{HASIL DAN PERANCANGAN}

\subsection{Desain Sistem Secara Umum}

Secara umum bentuk dari sistem robot pendeteksi halangan ini terdiri atas sistem mekanik dan rangkaian elektronik. Gerakan dari sistem mekanik akan ditentukan oleh gerakan simulasi yang digunakan, sedangkan rangkaian elektronika berfungsi untuk memberikan data berupa sinyal yang akan diproses oleh mikrokontroler sesuai logika program yang yang dirancang. Untuk menggambarkan sistem yang dibangun ini secara umum dan menyeluruh digunakan Data Flow Diagram yang terdiri dari :

\subsubsection{Context Diagram}

Context diagram adalah pendefenisian terhadap system yang akan dirancang yang bersifat menyeluruh. Context diagram digunakan untuk memudahkan proses penganalisaan terhadap system yang dirancang secara keseluruhan. Dalam hal ini context diagram berfungsi sebagai media yang terdiri dari suatu proses dan beberapa buag eksternal entity. Adapun context diagram yang dimaksud dapat dilihat pada gambar berikut :

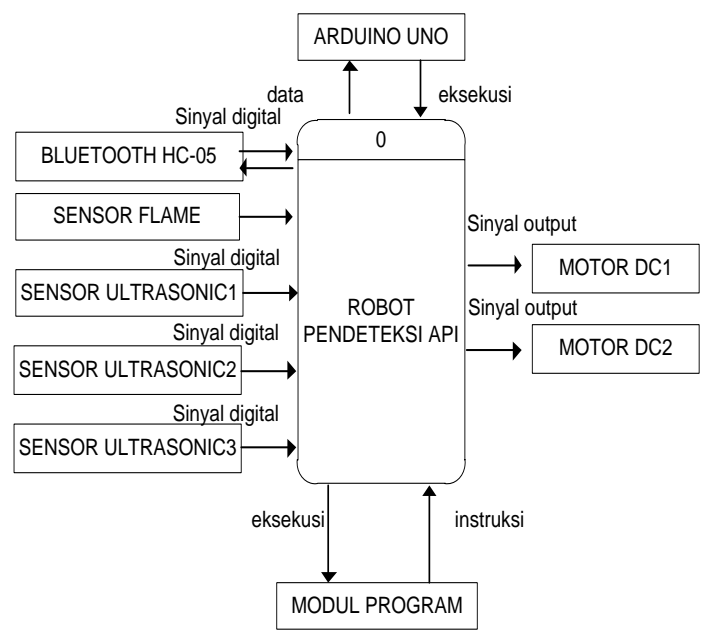

Gambar 3.1 Context Diagram 


\subsubsection{Bentuk Fisik Alat}

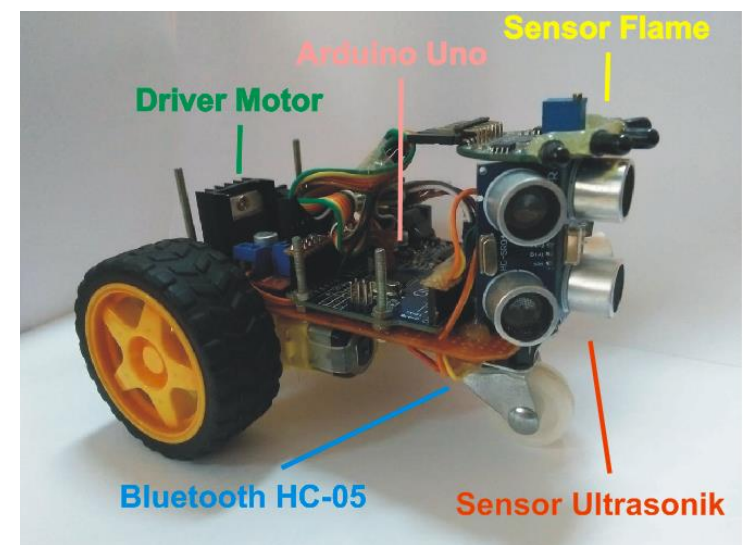

Gambar 3.2 Rancangan Fisik Alat

\subsubsection{Rancangan Modul Program}

Pada sub bab ini akan dijelaskan tentang modul program yang digunakan untuk mengontrol kinerja dari robot yang dirancang.

Bentuk Program :

1. Perintah otomatis dan manual pada robot

if (Serial.available())\{

BluetoothData=Serial.read();

if $\left(\right.$ BluetoothData $\left.=={ }^{\prime} \mathrm{C}^{\prime}\right)$ tombol=true;

if(BluetoothData=='c')\{tombol=false;Serial.print("*ZManual*");goto

manual; \}

if (tombol)\{ Serial.print("*ZOtomatis*"); goto awal;\}

\}

2. Jika Perintah Manual

if (Serial.available ()$)\{$

BluetoothData=Serial.read () ;

if(BluetoothData=='C')tombol=true;

if (tombol) \{Serial.print("*ZOtomatis*"); berhenti();goto awal;\}\}

||||||||||||||||||||||||||||||||||||||||||||||||||||||||||||||||||||||||||||||||||||||||||||||||||||||||||||||||||

I// Baca Perintah

if (tombol1) \{maju(); \}if (tombol2) \{ mutarkanan(); \}if (tombol3) \{mundur();\}

if (tombol4) \{ mutarkiri(); \}if (tombol5) \{mutarkanan(); \}if (tombol6) \{ mutarkanan();\}

if (tombol7) \{mutarkiri(); \}if (tombol8) \{ mutarkiri();

3. Jika Perintah Otomatis

if (Serial.available ()$)\{$

BluetoothData=Serial.read ();

if(BluetoothData=='c')\{tombol=false; Serial.print("*ZManual*"); berhenti(); goto manual;

if (tombol) \{ Serial.print("*SSistem Otomatis*");

||||||||||||||||||||||||||||||||||||||||||||||||||||||||||||||||||||||||||||||||||||||||||||||||||||||||||||||||||||||||||||

bacasensor();

sensorapi();

if(sensorkiri $>20 \& \&$ sensortengah $>20 \& \&$ sensorkanan $>20$ )

\{Serial.println("Maju"); pinmaju: maju();delay(5); 
while(1)

\{ sensorapi();

$$
\begin{gathered}
\text { if }(\mathrm{SS} 1==1\|\mathrm{SS} 2==1\| \mathrm{SS} 3==1\|\mathrm{SS} 4==1\| \mathrm{SS} 5==1)\{\text { goto deteksi; }\} \\
\text { else }\{\text { goto awal; }\}\}\}
\end{gathered}
$$

if(sensorkiri<20 \&\& sensortengah $<20 \& \&$ sensorkanan $>20$ )

mutarkanan(); delay(300);

\{halangan: Serial.println("Mutarkanan 300");

while(1)

\{ sensorapi () ;

$$
\begin{gathered}
\text { if }(\mathrm{SS} 1==1\|\mathrm{SS} 2==1\| \mathrm{SS} 3==1\|\mathrm{SS} 4==1\| \mathrm{SS} 5==1)\{\text { goto deteksi; }\} \\
\text { else }\{\text { goto awal; }\}\}\}
\end{gathered}
$$

if(sensorkiri<20 \&\& sensortengah>20 \&\& sensorkanan>20)

\{ Serial.println("Mutarkanan 300");

while(1)

mutarkanan();delay(300);

\{ sensorapi(); else $\{$ goto awal; $\}\}$ \}

if(sensorkiri<20 \&\& sensortengah $<20 \& \&$ sensorkanan $<20$ )

while(1)

\{Serial.println("ada api");adaapi:

\{goto awas; \}

while(1)

if(sensorkiri $>20 \& \&$ sensortengah $<20 \& \&$ sensorkanan $<20)$

\{ Serial.println("Mutarkiri 300"); mutarkiri(); delay(300);

\{ sensorapi();

$$
\begin{aligned}
& \text { if }(\mathrm{SS} 1==1\|\mathrm{SS} 2==1\| \mathrm{SS} 3==1\|\mathrm{SS} 4==1\| \mathrm{SS} 5==1)\{\text { goto deteksi; }\} \\
& \text { else }\{\text { goto awal; }\}\}\}
\end{aligned}
$$

if(sensorkiri $>20 \& \&$ sensortengah $>20 \& \&$ sensorkanan<20)

\{ Serial.println("Mutarkiri 300");

while(1)

mutarkiri();delay(300);

\{ sensorapi () ;

$$
\text { if(SS1==1 || SS2==1 || SS3==1 || SS4==1 || SS5==1)\{goto deteksi;\} }
$$

else $\{$ goto awal; $\}\}$ \}

while(1)

if(sensorkiri $<20 \& \&$ sensortengah $>20 \& \&$ sensorkanan $<20)$ $\{$ maju( $)$;

$\{$ sensorapi () ;

$$
\begin{gathered}
\text { if }(\mathrm{SS} 1==1\|\mathrm{SS} 2==1\| \mathrm{SS} 3==1\|\mathrm{SS} 4==1\| \mathrm{SS} 5==1)\{\text { goto deteksi; }\} \\
\text { else }\{\text { goto awal; }\}\}\}
\end{gathered}
$$

if(sensorkiri $>20 \& \&$ sensortengah $<10 \& \&$ sensorkanan $>20$ ) \{awas:

while(1)

\{ sensorapi(); bacasensor();

if(sensorkiri $<20 \& \&$ sensortengah $<10 \& \&$ sensorkanan $<20 \& \&$ $\mathrm{SS} 3==1 \& \& \mathrm{SS} 2==1$ || SS3==1 \&\& SS4==1)

$\{$ berhenti();delay(10000); \} else \{mundur1();delay(400); goto halangan;\}\} goto cariapi; \}

4. Sensor Mendeteksi Api

$$
\begin{aligned}
& \text { if }(\mathrm{S} 1==\mathrm{HIGH})\{\mathrm{SS} 1=1 ; \text { Serial.print }(" * \mathrm{QV} 100 * ") ;\} \\
& \text { if }(\mathrm{S} 2==\mathrm{HIGH})\{\mathrm{SS} 2=1 ; \text { Serial.print }(" * \mathrm{QV} 100 * ") ;\} \\
& \text { if }(\mathrm{S} 3==\mathrm{HIGH})\{\mathrm{SS} 3=1 ; \text { Serial.print("*QV100*"); }\} \\
& \text { if (S4 == HIGH) }\{\mathrm{SS} 4=1 ; \text { Serial.print("*QV100*"); }\}
\end{aligned}
$$




$$
\text { if }(\mathrm{S} 5==\mathrm{HIGH})\{\mathrm{SS} 5=1 ; \text { Serial.print }(" * \mathrm{QV} 100 * ") ;\}
$$

\subsubsection{Pengujian Sistem}

Pertama aktifkan Sistem Robot kemudian koneksikan Smartphone ke Bluetooth yang sudah di koneksikan dengan Robot, setelah terkoneksi kemudian jalan kan aplikasi pada smartphone. Tampilan aplikasi pada smartphone. Bisa dilihat seperti gambar berikut:

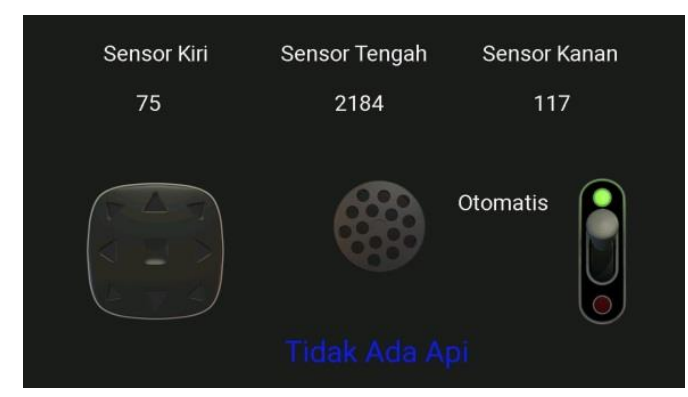

Gambar 3.3 Tampilan Aplikasi Smartphone Kondisi Otomatis dan Belum Mendeteksi Api

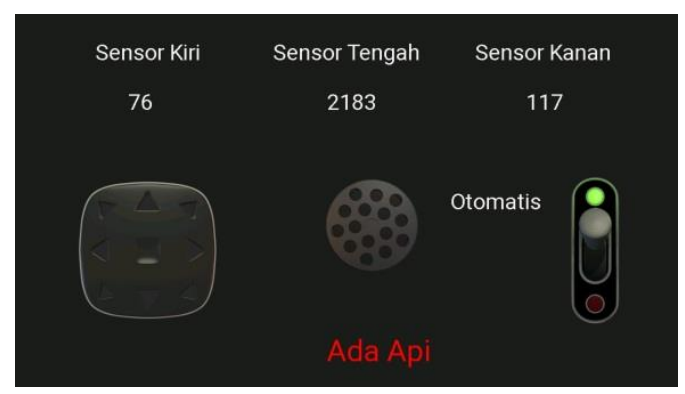

Gambar 3.4 Tampilan Aplikasi Smartphone Kondisi Otomatis dan Mendeteksi Api

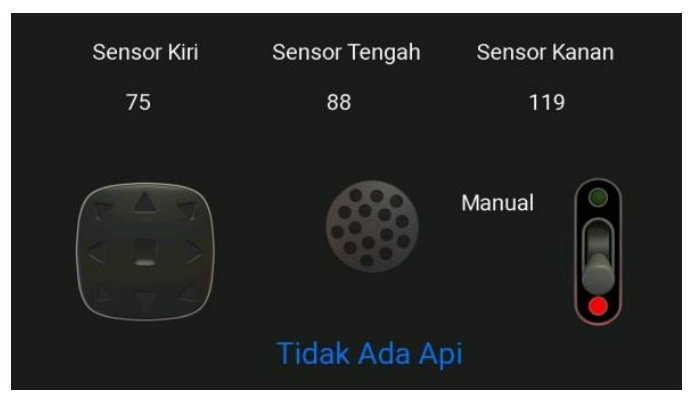

Gambar 3.5 Tampilan Aplikasi Smartphone Kondisi Manual dan Belum Mendeteksi Api

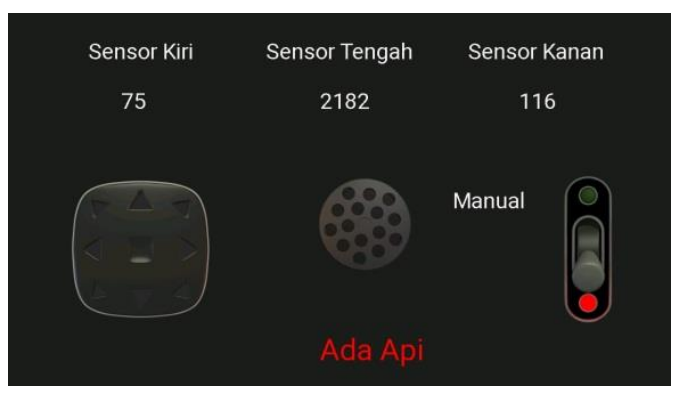

Gambar 3.6 Tampilan Aplikasi Smartphone Kondisi Manual dan Mendeteksi Api 
Dari Tampilan pada gambar tersebut adalah bisa dilihat aplikasi menampilkan kondisi halangan sensor depan, sensor kiri dan sensor kanan. Kemudian system pada robot juga bisa diatur kondisi manual atau otomatis.

Untuk Kondisi Manual, user yang harus menggerakan robot kearah mana pun dan sensor api akan terus mendeteksi api, dan apabila ada api maka sensor akan mengirim data ke Arduino dan Arduino akan mengirim data ke Bluetooth untuk menampilkan diaplikasi. Dan untuk otomatis robot akan bermanuver otomatis sesuai perintah yang kita masukkan kedalam robot. Dan apabila ada system pada robot juga akan memberi tahu bahwa ada api.

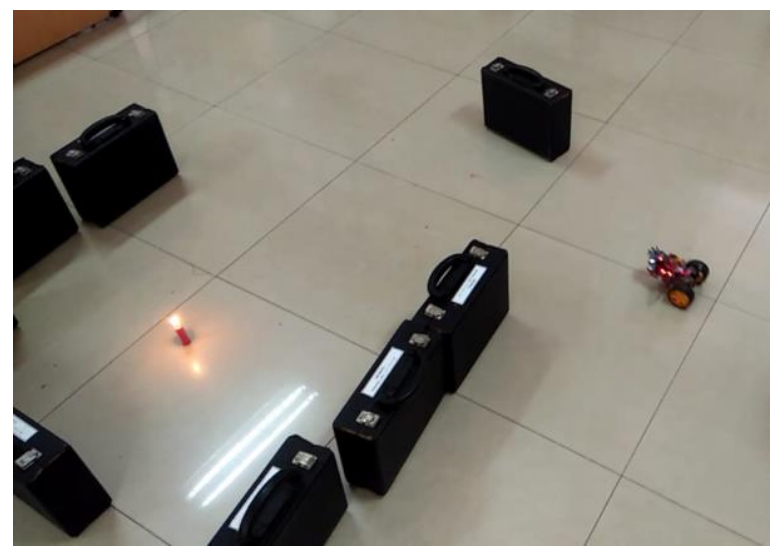

Gambar 3.7 Tampilan Robot Mencari Api

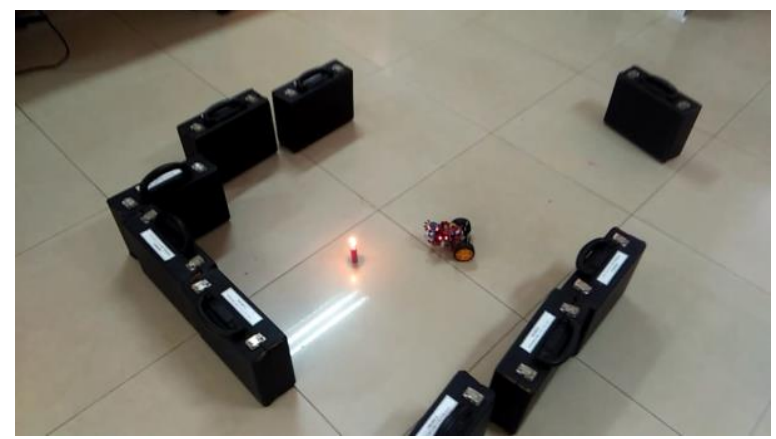

Gambar 3.8 Tampilan Robot Mendapatkan Titik Api

\section{KESIMPULAN}

Berdasarkan hasil pengujian yang telah dilakukan, dapat diambil kesimpulan-kesimpulan, yaitu:

a. Dengan menggunakan Sistem Otomatis dan Manual pada robot maka User akan lebih mudah mengontrol robot dalam pencarian titik api

b. Penerapan Sistem Konektifitas antara Smartphone dan Robot lebih mempercepat pemberitahuan keberadaan api dilingkungan robot bekerja.

c. Dengan adanya Robot pencari titik api. Akan mengurangi dampak besar terhadap kebakaran.

\section{DAFTAR REFERENSI}

[1] Ari Widiyatmoko, A. F. (2016). Robot Beroda Pemadam Api Dengan Pengolahan Sensor Api Berbasis Fuzzy Logic. Prosiding Seminar Nasional Elinvo, Vol 2.

[2] Ganti Depari. (1992). Belajar Teori dan Ketrampilan Elektronika. Bandung: PT. Elex Media Computindo.

[3] Hermanto, D. (2015). PENGONTROLAN GERAK MOBILE ROBOT MENGGUNAKAN SENSOR ACCELEROMETER PADA PERANGKAT BERGERAK ANDROID. CSRID, 1-11.

[4] Kusumadewi, S. (2003). Artificial Intelligence (Teknik dan aplikasinya). Yogyakarta: Graha Ilmu. Jurnal KomtekInfo Vol : 7 No : 1//2020 
[5] Malik, d. (1997). Bereksperimen dengan Mikrokontroler 8051. Jakarta: PT. Gramedia.

[6] Meshram, R. (2013). Motion Control of Wheeled Mobile Robots Using Fuzzy Logic. International Journal of Recent Technology and Engineering (IJRTE), 2.

[7] Nugraha, D. W. (2010). Perancangan Sistem Kontrol Robot Lengan Yang Dihubungkan Dengan Komputer. MEKTEK, 180-188.

[8] Pitowarno, E. (2006). Robotika: Desain, Kontrol, dan Kecerdasan Buatan. Yogyakarta: Andi.

[9] Rashid, R. E. (2010). Fuzzy-based Navigation and Control of a Non-Holonomic Mobile Robot. Journal Of Computing, 130-137.

[10] Wirawan, N. T. (2018). Pemanfaatan Smartphone Pada Robot Beroda Untuk Monitoring Jarak Robot Dengan Halangan Menggunakan Bluetooth Hc-05 Sebagai Media Komunikasi. Komtekinfo, 110-121. 